\title{
Perception of Teacher Support by Students in Vocational Education and Its Associations with Career Adaptability and Other Variables
}

\author{
Bohumíra Lazarová*, Petr Hlad’o, Lenka Hloušková \\ Department of Educational Sciences, Faculty of Arts, Masaryk University, Brno, Czech Republic \\ ${ }^{*}$ Corresponding author. E-mail: lazarova@phil.muni.cz
}

Background. Children and adolescents currently spend a great deal of time at school and teachers are viewed as a source of social support in different areas of their personal development, such as their career adaptability.

Objective. To provide insight into the way students in secondary vocational education perceive teacher support and to explore the association between perceived teacher support, career adaptability, and other demographic and academic variables.

Design. A questionnaire battery with two main tools, the Teacher Support Scale and the Career Adapt-Abilities Scale, was the data collection method. Subjects were students in the last year of full-time study at public secondary vocational schools and vocational upper-secondary schools. The sample comprised 3,028 participants aged 18-26.

Result. Students perceived the support of their teachers quite positively, with the difference between boys and girls not being statistically significant. The satisfaction of the student with the field of study, academic performance, and satisfaction with the academic success rate predict the perception of teacher support. The level of perceived teacher support positively correlates with students' overall career adaptability, as well as with all the dimensions of career adaptability, and is also a significant predictor.

Conclusion. Both key concepts, teacher support and career adaptability, have the potential to attract the attention of psychologists working in the educational system.
Keywords: teacher support; career adaptability; adolescents; vocational schools; school psychology 


\section{Introduction}

Children and adolescents currently spend a great deal of time at school and therefore there is no doubt that teachers are viewed as a source of social support, attracting the attention of a number of researchers across scientific disciplines. Respecting teacher support, it is useful to distinguish among provided, perceived, offered, and sought social support (Malecki \& Demaray, 2002). We have focused in this study on perceived teacher support.

While research on teacher support remains of rather marginal interest in the Czech Republic, the phenomenon of teacher support abroad has become a relatively frequent research topic, especially in quantitative research (Brewster \& Bowen, 2004; Caleon et al., 2017; Cox \& Williams, 2008; Dietrich, Dicke, Kracke, \& Noack, 2015; Filak \& Sheldon, 2008; Guess \& McCane-Bowling, 2016; Klem \& Connell, 2004; Mantzicopoulos \& Neuharth-Pritchett, 2003; McNeely \& Falci, 2004; Perry, Liu, \& Pabian, 2010; Reddy, Rhodes, \& Mulhall, 2003; Sakiz, Pape, \& Hoy, 2012; Suldo et al., 2009; Torsheim, Wold, \& Samdal, 2000; Zhang, Yuen, \& Chen, 2018, and others).

In this study, we introduce the findings of more comprehensively conceived quantitative research primarily focused on the exploration of career adaptability of adolescents, in particular students at vocational upper-secondary schools. We select and offer data related to the relationships between career adaptability and support that students perceive in connection with teachers. First of all, we frame the concept of teacher support in a broader theoretical and definition context, introduce the methodology of our research and the nature of the research tools used. In the following section, we describe, using the specific data, how specific groups of students perceive support from teachers and what relationship this perceived support has to some school-related variables and the career adaptability of the students.

\section{Definition of Teacher Support}

The definition of teacher support is not entirely uniform and this concept is understood differently in (not only) psychological theories. Teacher support, specified as the interaction between teachers and students, has long been examined in relation to the results of students' study, and thus completes the picture of effective and quality teaching. Teachers are no longer merely teaching experts, however, who provide academic support to students. They are seen as "natural mentors" (AlleeSmith, Im, Hughes, \& Clemens, 2018), "first line" career counsellors (Schiersmann et al., 2012), and are often associated with the role of the "caring person" (Caen, 2011). In this context, it is not surprising that the teacher's ability or skill in providing support to students and creating positive relationships with them is included in the lists of teacher competences and becomes a topic of professional development.

The definition of teacher support may be associated with Tardy's model of social support (Tardy, 1985), which defines the support of teachers as a series of strategies utilized by those teachers. Support may be observed in the emotional, instrumental (physical assistance), information and valuation, and appraisal areas (cf. Malecki \& Demaray, 2003). Zhang and Chen Yuen (2018) conclude that teacher support may also be seen in relation to career development from the perspective of 
social support, which is based on social relations and close interpersonal interactions between students and teachers. This kind of support may not only lead to the fulfilment of specific goals, but may also contribute to solving individual problems, strengthening overall well-being, feeling safe, and good mental health.

Teacher support may also be seen as a natural part of the school environment, or rather as one of the key dimensions of the class and school climate (Cox \& Williams, 2008; Ryan \& Patrick, 2001). In connection with this approach, ecological systems theories pointing out the importance of the school as an eco-system (Bronfenbrenner, 1979) are emphasized, as well as the social setting theory that follows from Bronfenbrenner's theory (Tsen \& Seidman, 2007). Both theories accentuate the creation of supportive relationships between the actors of the school environment as part of the social processes that take place in schools "naturally". The social setting theory implies that if we want to achieve educational change in the broad sense of the word, relationships among people at school, including the relationships between teachers and students, have to be changed as well.

Ryan and Deci's self-determination theory, which is mentioned quite often in relation to schoolwork and career choice, may be stated as another theoretical basis of teacher support (Deci \& Ryan, 2000). According to this theory, the purpose of teacher support is to develop the students' intrinsic motivation by promoting their autonomy, respecting their interests, and promoting their creativity and effort to succeed (cf. Filak \& Sheldon, 2008; Ryan \& Patrick, 2001, and others). Such support is related to developing students' abilities to take a leading role (to develop self-regulation), to develop self-confidence and self-esteem, and to a sense of self-efficacy, responsibility, and persistence (Klem \& Connell, 2004; Metheny, McWhirter, \& O’Neil, 2008; Mitchell \& DellaMattera, 2010; Zhang, Yuen, \& Chen, 2018).

Rogers' humanistic approach to person-centered counselling/therapy teaching, which emphasizes the helping relationship in all areas of work with people and stimulates the individual potential for self-development (Rogers, 1958), is also worth mentioning. In this context, the relationship between the teacher and student is considered a key pillar of any support, regardless of its objectives.

\section{Measurement of Teacher Support and Its Behavioural Image}

Teacher support is usually examined through subjective assessment by students using a variety of quantitative tools. Unlike instruments measuring the perceived level of parent support, the tools assessing the perceived level of teacher support have one disadvantage: While the subject providing the support is clearly defined in the case of parents (e.g., Hlado \& Ježek, 2018), it is not always clear which of the teachers is involved on the basis of the questionnaires aimed at evaluating teacher support. In fact, there are usually several teachers taking turns in the class, and the respondent may respond or may even have to respond in relation either to one particular teacher (items like "this teacher of mine...", "my teacher..."), or to all the teachers (items like "my teachers...", "most teachers ...", "our teachers...", "the majority of teachers..."). In the first case, it is an "evaluation" of the work of a particular teacher and research may then be applied to, for example, teachers of different subjects, comparing their support (Dietrich et al., 2015), while in the second case, the supportive character of the overall climate in a class or school is assessed. 
Researchers use complex tools either to measure (a) the climate of a class or school where teacher support plays an important role, or (b) perceived social support where the teacher is only one of the potential people providing support to individuals in different life situations or phases. Metheny, McWhirter, and O'Neil (2008) report that they found 16 tools focused on the perception of teacher support, of which only 4 were stand-alone tools and 12 were subscales or factors of more complex tools. They consequently often contained a small number of items, which may be seen as a limiting factor in terms of validity.

The following tools may be mentioned as examples of comprehensively conceived tools focused on social climate: the Classroom Environment Scale (CES) (Moos \& Trickett, 1974), The School Environment Measure (cf. Wang \& Eccles, 2013), the Research Assessment Package for Schools (RAPS) (1998), and the Learning Climate Questionnaire (LCQ) (Williams \& Deci, 1996). Tools focused on social support include: the Social Support Questionnaire (Sarason, Levine, Basham, \& Sarason, 1983), the Social Support Scale for Children and Adolescents (SSSCA) (Harter, 1985), the Child and Adolescent Social Support Scale (CASSS) (Malecki \& Demaray, 2003), the Classroom Life Measure (Johnson \& Johnson, 1983), and the Teacher and Classmate Support Scale (TCMS) (cf. Wold, Aarø, \& Smith, 1994).

Scales directly designed to measure teacher support either have a general purpose or identify a specific type of support (learning, motivation, autonomy, career development, relationship to the teacher, etc.). It is worth mentioning, for example, Young Children's Appraisals of Teacher Support (Y-CATS) (Mantzicopoulos \& Neuharth-Pritchett, 2003), Teacher Treatment Inventory (Weinstein, Marshall, Sharp, \& Botkin, 1987), Teacher Support (Lapan, Tucker, Se-Kang, \& Kosiulek, 2003), Teacher Support Measurement (Farmer, 1985), and the like.

According to Zhang, Yuen, and Chen (2018, p. 127), the Teacher Support Scale (TSS) by McWhirter in the modification of Metheny, McWhirter, and O'Neil (2008) - which has been used in our research - is the most frequently used tool in career decision support studies (more about this tool is provided in the next section).

The definitions of teacher support, as well as the dimensions of the tools for its measurement, reflect teacher behavior that is perceived as supportive. It is almost impossible, however, to answer the question as to what kind of behavior or targeted practices the teacher actually uses to support the students. It seems that the factors associated with supportive behavior of teachers may be classified as, for example, concrete help in problems or achieving goals, help in planning for the future (Harter, 1985); care (involvement with the student), which includes the interest or concern of the teacher about the student, including the anticipation of potential problems (Harter, 1985; Klem \& Connell, 2004); fairness; providing some structure or rules, including the formulation of clear expectations (fair, positive expectation) (Harter, 1985; Klem \& Connell, 2004; Metheny, McWhirter, \& O’Neil, 2008; RAPS, 1998); direct negotiation, engagement, or accessibility - teacher activity and availability are expected here (treats, investment, accessible) (Harter, 1985; RAPS 1998; Metheny, McWhirter, \& O'Neil, 2008), positive perception of the student (positive regard), which expresses optimism, confidence and relationship (Metheny, McWhirter, \& O’Neil, 2008), and warmth and listening (Mantzicopoulos \& Neuharth-Pritchett, 2003). 
Similarly, Ryan and Patrick (2001), based on delimitation chosen by various authors, summarize that the definitions of teacher support operate with concepts such as caring, friendliness, understanding, dedication, and dependability.

It is clear that the behavioral image of the provided support reflects the personal characteristics of the teachers. Although teachers often try to provide support through targeted action, the relationship between the teacher and student, which is difficult to capture using the tools designed to measure teacher support, is the key determinant of effectiveness.

\section{Effects of Teacher Support}

Although teacher support is defined in various ways, researchers agree that it is a crucial factor that affects emotional development; that it is related to the experience and behavior of students (Brewster \& Bowen, 2004; Cox \& Williams, 2008; Dietrich et al., 2015; Filak \& Sheldon, 2008; Guess \& McCane-Bowling, 2016; Reddy, Rhodes, \& Mulhall, 2003; Suldo et al., 2009); and that it influences student motivation and academic performance (Klem \& Connell, 2004; Perry, Liu, \& Pabian, 2010) as well as career decisions and career development of students (Metheny, McWhirter, \& O’Neil, 2008).

With respect to the above-mentioned efforts to differentiate the types of teacher support, Zhang, Yuen \& Chen (2018) agree that it may be difficult to distinguish specifically focused support (e.g., on career) and generally focused support. Research has shown that any effective teacher support may have a direct or indirect impact on class or school climate, increases encouragement of students, school engagement, connectedness to school, affinity for school, sense of belonging to the school, interest in education, as well as well-being and mental health (Allee-Smith et al., 2018; Brewster \& Bowen, 2004; Filak \& Sheldon, 2008; Guess \& McCaneBowling, 2016; Klem \& Connell, 2004; McNeely \& Falci, 2004; Perry, Liu, \& Pabian, 2010; Ryan \& Patrick, 2001; Sakiz, Pape, \& Hoy, 2018; Suldo et al., 2009; Wang, \& Eccles, 2013).

Perceived teacher support has a demonstrable relationship to motivation of student performance and academic engagement (Cooper, 2014; Ruzek et al., 2016). If students in a class perceive the support of their teacher, they show more interest and enjoyment of their schoolwork, more self-esteem, and higher expectations of school success (Ryan \& Patrik, 2001). There is no research consensus, however, about the impact of teacher support on the students' academic results (Caleon et al., 2017; Klem \& Connell, 2004; Ryan \& Patrick, 2001). While there is no doubt about the positive impact of teacher support, it is impossible to unequivocally prove specific benefits from a certain type of supportive teacher behavior. There are always many intervening variables that play a role. It is clear, however, that teacher support based on a good relationship has synergistic effects and is beneficial in many ways.

The effects of support are in some cases monitored for selected groups of students. The authors of such research (e.g., Brewster \& Bowen, 2004; Caleon et al., 2017; McNeely \& Falci, 2004; Perry, Liu, \& Pabian, 2010) intentionally focus on providing support to at-risk or disadvantaged groups of students (ethnic differences, school failure, learning disabilities, problematic behavior or emotions, maladaptation, etc.). The importance of the relationship between teachers and students 
and the supportive effect of teachers increases especially in cases where good parental support is lacking (Perry, Liu, \& Pabian, 2010; Sakiz et al., 2012). At the same time, however, some cognitive and behavioral stereotypes of teachers work against certain groups of students who are actually given less support, and students may also perceive it in such a way. Students whose teachers expect more from them are believed to benefit from more teacher support (Caleon et al., 2017). Adolescent students who are at risk of losing motivation and leaving school early are considered one of the risk groups. Non-parental adults (among them teachers) are important for adolescents as role models and sources of support, for example, in the area of career decision-making (Metheny, McWhirter, \& O’Neil, 2008; Perry, Liu, \& Pabian, 2010).

\section{Career Adaptability}

Current research in the field of vocational psychology emphasizes the need to explore more deeply the quality of relationships between people in connection with career development (Metheny, McWhirter, \& O’Neil, 2008). Some studies have examined the impact of teacher support on career planning (Perry, Liu, \& Pabian, 2010) and self-efficacy in career decision-making (Di Fabio \& Kenny, 2015). It has become a challenge for us to explore the relationship between perceived teacher support and career adaptability, which is a concept that reflects the resources of a person for career management and suggests the ability of an individual to cope with current and anticipated tasks, transitions, and traumas in vocational roles (Savickas \& Porfeli, 2012).

The concept of career adaptability is based on the career construction theory (Savickas, 2005) and includes four dimensions: the concern of individuals about their future, including planning; control over their own lives, the ability to be active in such matters and make decisions; curiosity about career possibilities and alternatives; confidence in achieving career goals, dealing with obstacles and challenges in their careers. From this perspective, career adaptability is a meta-competence which may make it easier for individuals to move from education to the labor market and deal with unexpected or planned career changes.

Kenny and Bledsoe (2005) examined teacher support along with parental support and support of close friends in relation to upper-secondary-school students' career adaptability and concluded that the emotional support of family, teachers, and close friends, when assessed together, makes a significant contribution to all four dimensions of career adaptability. Students who perceived greater support manifested higher levels of career adaptability. The authors of the study also indicated that different sources of social support contributed differently to individual dimensions of career adaptability. It is therefore apparent that targeted support from different sources is related to career adaptability.

\section{Research Methodology}

\section{Study Objectives}

The theoretical overview shows that a great deal of attention is paid abroad to research on teacher support. It is primarily studied, however, in relation to students 
of lower-secondary education. In the Czech environment, social support by teachers is a neglected topic. Therefore, the first objective of the present study is to describe how teacher support is perceived by students of vocational upper-secondary schools and whether and how perceived teacher support is related to the selected characteristics of students.

As can be seen from the research findings, teacher support may have a positive impact on entire school classes as well as various aspects of the life of adolescents (not only at school): mental health, school performance, self-esteem, or career decision. In our broadly conceived research, we focused not only on the relationship between career adaptability and teacher support, but we also sought to identify other potential impacts of perceived teacher support that have not hitherto been at the center of research attention. We thought that there could also be a relationship between perceived teacher support, the method of completing secondary school education, satisfaction with the field of study, etc. Due to the absence of current knowledge about the specific impact of teacher support on the career development of students, the second objective of this study was to identify the relationship between teacher support and career adaptability of students in the last years of uppersecondary schools, students who are currently facing choices about further education and a career path.

\section{Participants and Procedures}

The study presents partial findings from the first wave of data collection within the framework of longitudinal research (2018-2020). Students in the last year of fulltime study at public vocational upper-secondary schools in the South Moravian and Moravian-Silesian Regions in the school year 2017-2018 were the investigated subpopulation. Based on the Statistical Yearbook of Education (MEYS, 2018), the basic set comprised 15,750 students. In both regions, head teachers of all vocational upper-secondary schools were asked by the Education Department of the respective region to participate in the research.

A questionnaire battery distributed to students through the school where they were studying was the main method of data collection. Administration took place either in an electronic or a printed form, according to the technical possibilities available and preferences of the head teachers of the individual schools. Data collection took place in March and April 2018 at 44 schools (21 from the South Moravian Region and 23 from the Moravian-Silesian Region). After signing the informed consent, students filled out questionnaires voluntarily during their lessons in the presence of a trained teacher, who provided them with the necessary assistance, if needed, while filling out the questionnaires.

A total of 3,126 students filled out the questionnaires, and 98 measurements were removed from the data file (e.g., answers to all items were the same, repeating answers of the type 123454321 , etc.). As a result, the sample was reduced to 3,028 respondents: $46.5 \%$ girls and $53.5 \%$ boys, aged $18-26(M=18.97 ; S D=1.09) ; 63.2 \%$ of them were in a field of study ending in a school-leaving examination (usually four-year study) and 36.8\% in a field of study ending in an apprenticeship certificate (usually three years of practically oriented study). The participants studied in a wide range of fields, including business economics, hospitality and tourism, nurs- 
ing, sport management, cosmetics, construction, gastronomy, and training to be a hairdresser, salesclerk, electrician, plumber, tinsmith, carpenter, joiner, auto mechanic, agricultural machinery technician, or agricultural producer/farmer, among others. Although we do not pay attention primarily to the family features and its support, in order to better describe our sample we add that $55.1 \%$ lived with their father and mother, $16.1 \%$ lived only with their mother, $4.1 \%$ lived only with their father, and $24.7 \%$ in other family structures; $14.3 \%$ of mothers and $15.3 \%$ of fathers had completed tertiary education; $78.8 \%$ of mothers were employed, $7.9 \%$ had a business, $1.4 \%$ were unemployed, and $12.0 \%$ had a different status (e.g., on maternity leave, housewives, had an disability pension); $69.1 \%$ of fathers were employed, $21.3 \%$ had a business, $1.2 \%$ were unemployed, and $8.4 \%$ had a different status. According to the last Population and Housing Census (Czech Statistical Office, 2019) in 2011, national and ethnic minorities in the Czech Republic accounted for only about $3 \%$ of the population. For this reason, neither the nationality nor the ethnic origin of participants needed to be assessed.

\section{Measures}

The Teacher Support Scale (TSS; Metheny, McWhirter, \& O’Neil, 2008) was included in the questionnaire battery, in which the respondents commented on 21 statements using a 5-point Likert scale ranging from 1 (strongly disagree) to 5 (strongly agree). The items do not refer to individual teachers, but to the teaching staff in general. The chosen tool reflects teacher support as a social phenomenon. The original version of the tool is composed of four subscales: interested (example item: "Teachers are interested in my future"), positive regard (example item: "Teachers would tell other people good things about me"), expectation (example item: "Teachers expect me to work hard in school"), and accessible (example item: "Teachers are easy to talk to about school things"). Various authors using the scale report an internal consistency ranging from .91 to .97 (Perry, Liu, \& Pabian, 2010).

The English version of the tool was first translated into the Czech language by a professional translator and later back-translated by a bilingual translator. The abovementioned four factors were not confirmed for the Czech version by confirmatory factor analysis (CFA) of the tool. Two models were tested - correlated factors (M1) and a hierarchical model (M2). Both models were specified and estimated in lavaan (version 0.6-2, Rosseel, 2012) using the WLSMV estimator with ordinal items. M1's fit with the data is barely acceptable, $\chi^{2}(183)=4707, p<.001$, CFI $=.93$, $\mathrm{RMSEA}=.098, \mathrm{SRMR}=.050$. Correlations between factors are very high, ranging from .71 to .99. In fact, the estimated latent variable variance-covariance matrix psi is not positive-definite, suggesting estimation problems of a model with poorly differentiated factors. The same problems show up in the hierarchical model (M2), the estimation of which results in an inadmissible solution with negative variance (disturbance) of one of the factors and one standardized loading over 1 . The fit of M2 is similar to that of M1, $\chi^{2}(185)=4653, p<.001, \mathrm{CFI}=.93$, RMSEA $=.097$, SRMR $=.051)$. Overall, the structure reported by Metheny, McWhirter, and O'Neil (2008) does not seem to be well supported by our data. The dimensionality of our data appears to be lower, so we decided to use exploratory factor analysis (EFA) to 
evaluate it. The analysis resulted in a bifactor model with one central factor and items from the original factor of positive perception that make up the so-called facet. Items of positive perception reflect the specific form of indirect teacher support, which is manifested in the student's belief that teachers view him/her positively, which means the emotional support in Tardy's social support model (Metheny, McWhirter, \& O'Neil, 2008). The bifactor model corresponds well to the data, $\chi^{2}(172)=3035, p<.001, \mathrm{CFI}=.955$, RMSEA $=.079, \mathrm{SRMR}=.041$. Although the overall TSS scale has a high internal consistency (McDonald's $w=.90)$, the facet does not have it (McDonald's $w=.26)$. For this reason, we worked predominantly in our study with teacher support expressed by the total TSS score from all the tool items.

The Czech version of the internationally established Career Adapt-Abilities Scale - International Form 2.0 (CAAS; Savickas \& Porfeli, 2012) was used to determine career adaptability (Hlado, Kvasková, Ježek, Hirschi, \& Macek, 2019). The tool has 24 statements that illustrate different skills that are important for career decision-making; the respondents comment using a 5-point Likert scale from 1 (not strong) to 5 (strongest). The tool measures four dimensions of career adaptability: concern, control, curiosity, and confidence. Confirmation factor analysis (CFA) confirmed the same factor structure as in the original version, $\chi^{2}(248)=3584$, $p<.001, \mathrm{CFI}=.93, \mathrm{RMSEA}=.069, \mathrm{SRMR}=.045$. Cronbach's $\alpha$ for total career adaptability was .93 and with respect to the individual subscales, it ranged from .80 to .88 .

The questionnaire battery also included items related to the students' family background (parental education, employment of parents, family structure, etc.) and other selected academic variables (academic performance, satisfaction with the academic success rate, educational aspirations, etc.).

\section{Statistical Analyses}

A latent regression analysis was used to examine links between variables. The tests compare the means of the latent TSS variable, and individual covariates as TSS predictors are gradually added to the TSS measurement model. For these statistical analyses, the software environment $\mathrm{R}$ with the Lavaan package (v. 0.6-3) was used. Statistical differences in the responses of different respondent groups to individual TSS items were determined by the t-test for two independent selections using the program IBM SPSS (v. 23).

\section{Results}

It should be stated first that each student perceives his/her teachers differently and thus perceives teacher support differently as well. At the same time, teacher support may be perceived as social classroom phenomena shared in the individual classes. These results are therefore to be understood as a general trend going "across" the classes and teachers of individual subjects (Dietrich et al., 2015).

As we could not rely on the individual factors of teacher support (because they were not confirmed by the factor analysis), we used the analytical approach to compare the individual item averages to see in which specific areas students perceive 
teacher support the most strongly and in which areas they perceive it less strongly, while comparing certain groups of students according to the set variables. The average values are shown in Table 1.

Table 1

Teacher Support Scale - item means and descriptive statistics

\begin{tabular}{clrr}
\hline $\begin{array}{c}\text { Item } \\
\text { number }\end{array}$ & $\begin{array}{l}\text { Item } \\
\text { “Most teachers in my high school...” }\end{array}$ & M & SD \\
\hline 1 & Expect me to work hard in school & 4.02 & .96 \\
2 & Try to answer my questions & 3.67 & 1.04 \\
3 & Are interested in my future & 2.82 & 1.19 \\
4 & Take the time to help me get better grades & 3.28 & 1.15 \\
5 & Think I am a hard worker & 3.27 & 1.11 \\
6 & Are helpful when I have questions about career issues & 3.55 & 1.06 \\
7 & Are helpful when I have questions about school issues & 3.73 & 1.01 \\
8 & Would tell other people good things about me & 3.28 & 1.05 \\
9 & Push me to succeed & 3.27 & 1.08 \\
10 & Challenge me to think about my future goals & 3.04 & 1.14 \\
11 & Believe I am smart & 3.32 & 1.02 \\
12 & Help me understand my strengths & 2.95 & 1.05 \\
13 & Want me to do well in school & 3.49 & 1.05 \\
14 & Enjoy having me in their classes & 3.22 & 1.06 \\
15 & Care about what happens to me & 3.01 & 1.04 \\
16 & Encourage me to learn & 3.33 & 1.08 \\
17 & Think I should continue my education after high school & 3.39 & 1.16 \\
18 & Support my goals for the future & 3.05 & 1.07 \\
19 & Will listen if I want to talk about a problem & 3.32 & 1.08 \\
20 & Are easy to talk to about school things & 3.53 & 1.02 \\
21 & Are easy to talk to about things besides school & 3.27 & 1.09 \\
\hline & & &
\end{tabular}

Note: 1 (strongly disagree) -5 (strongly agree)

The overall score of perceived teacher support (the total average value from the 5-point scale) is $3.33(S D=.71)$, which means that students perceive teacher support quite positively. If we focus on the items with the highest averages $(1,2,6$, $7,13$, and 20$)$ and the lowest averages $(3,10,12,15$, and 18$)$, then it may be stated that students perceive teacher support primarily in relation to success in school and other educational and career path issues that include both expectation $(1,13)$ and specific help $(2,6,7,20)$. They perceive their teachers somewhat less as people who are interested in them as "individuals" and support them in self-knowledge 
and thinking about their future - i.e., they perceive teacher support poorly when considering their teachers in the role of "career counsellors" (Schiersmann et al., 2012).

The standard deviations indicate the highest correspondence in responses to items $1,7,11,20(S D=.97$ to 1.02$)$ and the lowest correspondence in responses to items $3,4,10$, and $17(S D=1.14$ to 1.19$)$. Students agree the most that teachers expect them to work hard, but at the same time are available and helpful in school matters. This would mean that students in vocational education perceive teacher support primarily in relation to school matters, whereas teacher support as individualized assistance linked to the student's future is perceived by each of them in a different way.

We also focused our attention on assessing gender difference in the perception of teacher support. Girls perceive greater teacher support by $.03 \mathrm{SD}$ on average than boys $(z=.81, p=.420,95 \%$ CI $[-.05, .11]$, Cohen's $d=.03)$; however, the difference between boys and girls is not statistically significant. Statistically significant differences between boys and girls were recorded in relation to items no. 1, 5, $7,13,17$, and 20 (in favor of girls, $p<.05$ ) and only in the case of item 10 , did boys experience greater support (thinking about future goals, $p<.01$ ). The greatest difference was recorded with respect to item 5: Girls think that teachers encourage them to be diligent more than boys do $(p<.001)$. The above-mentioned differences could indicate that students perceive teacher support in the spirit of certain gender stereotypes, such as that "girls are diligent, so as a teacher I can expect them to work hard at school and therefore they deserve to be successful at school and have a 'better' educational future. In contrast, boys need to be encouraged to plan their future".

\section{Relationship of Teacher Support to School and Academic Variables}

We will now focus on the relationship between teacher support and the method of completing secondary school education, satisfaction with the field of study, academic performance, satisfaction with the academic success rate, willingness to work or continue studying in the given field, , and educational aspirations. In our sample, $63 \%$ of the students studied in fields ending with the school-leaving examination and $37 \%$ studied in fields ending with the apprenticeship certificate. Students in vocational education ending with the school-leaving examination perceived less teacher support on average by $.09 \mathrm{SD}$ than students ending with the apprenticeship certificate $(z=-2.06, p<.05,95 \%$ CI $[-.17,-.01]$, Cohen's $d=.09)$. There is, however, a statistically significantly higher level of support perceived by students in fields of study ending with the school-leaving examination in relation to items 1,17 , and $20(p<.05)$ - i.e., they feel that teachers expect them to work hard, think they should continue in their studies, and in this spirit probably also discuss school matters.

We were also interested in how satisfaction with the field of study is related to perceived teacher support. More than $77 \%$ of students in our sample expressed satisfaction with their field of study $(21.8 \%$ were very satisfied, $54.7 \%$ were rather satisfied). It turned out that greater satisfaction with the field of study posi- 
tively predicts the perception of teacher support $(B=.48,95 \%$ CI $[-.53,-.42]$, $z=-18.00, p<.001, r=-.35)$. Students who are satisfied with their field of study perceive greater teacher support in relation to all the questionnaire items $(p<.01)$. It may be assumed that students who are more satisfied with their field of study may be more motivated and more successful at school, which is also positively reflected in terms of support from teachers. Similarly, it can be assumed that students with higher academic performance ${ }^{1}$ or at least expressing satisfaction with their study results are more likely to receive greater support from their teachers. In our sample, $53 \%$ of students showed excellent or good results of study (excellent $6.4 \%$, very good $5.5 \%$, good $41.0 \%$ ) and $68 \%$ of students were satisfied with their study results (19.1\% satisfied, $49.0 \%$ rather satisfied). The analysis of the data showed that the results of study $(\mathrm{B}=-.19,95 \% \mathrm{CI}[-.23,-.14], z=-8.29, p<.001$, $r=-.16)$ and satisfaction of the student with the academic success rate $(B=-.29$, $95 \% \mathrm{CI}[-.34,-.24], z=-11.63, p<.001, \mathrm{r}=-.23)$ positively predict the perception of teacher support.

With respect to subjective assessment by the respondents, it seems that the assumptions that teachers seem to communicate more and take more care of students who have better academic performance, and that students with better results of study seem to use the support more, proves to be valid.

\section{Relationship Between Teacher Support and Career Adaptability}

Career adaptability of students is at the heart of our research project (e.g., Hlado, Lazarová, \& Hloušková, 2019) and we were interested in whether and how perceived teacher support is related to career adaptability. The level of perceived teacher support positively correlates not only with overall career adaptability, but also with all its dimensions: concern, control, curiosity, and confidence (Table 2).

Table 2

Correlation matrix of the TSS and career adaptability

\begin{tabular}{lccccc}
\hline \multicolumn{1}{c}{ Variable } & $\mathbf{1}$ & $\mathbf{2}$ & $\mathbf{3}$ & $\mathbf{4}$ & $\mathbf{5}$ \\
\hline 1. Concern & - & - & - & - & - \\
2. Control & .64 & - & - & - & - \\
3. Curiosity & .62 & .78 & - & - & - \\
4. Confidence & .67 & .80 & .78 & - & - \\
5. Career adaptability (total score) & .83 & .90 & .90 & .92 & - \\
6. Teacher Support Scale (TSS) & .30 & .27 & .29 & .31 & .33 \\
\hline
\end{tabular}

Note. All correlations are $p<.001$.

$1 \quad$ Academic performance was assessed by item: "How would you describe your learning outcomes in this school year?" Respondents may choose one of five options: excellent very good, good, sufficient, insufficient. 
With regard to the correlations found, we wanted to assess the predictive power of perceived teacher support for career adaptability and its dimensions. The first model $\left(\chi^{2}(929)=5597, p<.001, \mathrm{CFI}=.986\right.$, RMSEA $\left.=.046, \mathrm{SRMR}=.043\right)$ confirmed the significant effect of perceived teacher support on overall career adaptability $(\beta=.23, p<.001)$. In the second model, $\left(\chi^{2}(921)=5152, p<.001, \mathrm{CFI}=.987\right.$, RMSEA $=.044$, SRMR $=.040)$, teacher support was found to be a significant predictor of dimensions of career concern $(\beta=.23, p<.001)$, control $(\beta=.13, p<.001)$, curiosity $(\beta=.19, p<.001)$, and confidence $(\beta=.21, p<.001)$.

\section{Discussion}

The research results demonstrate that statistically significant relationships among perceived teacher support, certain school-related variables, and the career adaptability of adolescents may be taken into consideration. No association was found, however, between perceived support of teachers and the gender of students.

Some relationships between perceived teacher support and the academic variables of adolescents suggest various interpretations. There are different possible explanations if there is a lower level of perceived teacher support in the case of students in fields of study ending with the school-leaving examination than for their peers from fields of study ending with the apprenticeship certificate. We may take into account the assumption that students ending their study with the school-leaving examination are more independent and seek less support from teachers. There also exists an explanation that students in the fields ending with the apprenticeship certificate have a closer relationship with their teachers, as there are practical lessons in smaller groups that provide more opportunities for close cooperation, and this is bound to intensify communication between teacher and student. There is also the question as to whether student apprentices tend to have more worries in the course of their study, and therefore attract the attention of teachers more often. This assumption is excluded, however, by several findings. Students in the fields of study ending with the apprenticeship certificate were slightly more satisfied with the results of their study at school than students in fields of study ending with the school-leaving examination. In addition, the students in fields ending with the apprenticeship certificate had on average worse academic performance than students in fields ending with the school-leaving examination (although the differences between the two groups were not statistically significant), and, as presented in the Results section, students with worse academic performance perceive less teacher support. The question is whether students with worse results of their study are less interested in learning or in the field of study and therefore have less motivation to study. Such students would then logically not seek support at school. There may therefore be a joint "resignation on the part of students and teachers". If the teacher sees that the student is not interested and support has no motivational or other effects, the teacher prefers to pay attention to other students. In line with this idea, the findings of authors of another research project suggest that the students from whom teachers expect more may benefit from greater teacher support (Caleon et al., 2017; Faitar \& Faitar, 2013).

Positive relationships between the concepts closely related to career adaptability (e.g., self-efficacy in career decision-making, career planning, career prepa- 
ration) and perceived teacher support are documented by other research (e.g., Metheny, McWhirter, \& O’Neil, 2008, 2008; Perry, Liu, \& Pabian, 2010; Ryan \& Patrick, 2001). Our knowledge of the positive relationship between career adaptability and perceived teacher support corresponds to those findings. It appears that perceived teacher support, especially at a time when students have to cope with the transition from secondary school to tertiary education or the labor market, may significantly influence students' career adaptability and thus their future career prospects. Since we have conducted a cross-sectional study without longitudinal exploration, the expected direction of action of the variables may be reversed or even bidirectional. There consequently exists an interpretation that students with greater concern and confidence are the ones who themselves more often ask for the support of teachers.

These results then evoke a number of questions related to teacher training. Teacher competences and their readiness to provide effective and versatile support to students, without being solely career counsellors, may attract increased attention. Even support targeted in a broad way seems to provide adolescents with a wide range of benefits when it comes to planning or deciding on their further career.

With regard to the wording of the items, it is clear that we have measured how students perceive the support of teachers "as a team", which may be closely linked to the way students perceive the school social climate. If we conceive of perceived teacher support as part of the climate of classes or schools, then our findings are only partially consistent with Kaur's (2012) research, which confirms the relationship between the school climate and career maturity in the dimension of self-appraisal. Our research does not confirm, however, the relationship between the school climate and career planning. On the contrary, our results indicate a significant relationship between career adaptability in the dimension of concern, which also includes the ability to plan the future, and perceived support of teachers.

\section{Conclusion}

Both key concepts that have been our focus, teacher support and career adaptability, attract or at least have the potential to attract the attention of psychologists working in the educational system. In our research, we used two foreign tools (the Teacher Support Scale and the Career Adapt-Abilities Scale), which are not commonly used in the Czech Republic. We presented their partial properties and "diagnostic" potential using the data from a specific group of adolescents. The large set of respondents provides a relative guarantee of relevant findings, although we are aware the results and conclusions need to be considered in the light of limitations.

\section{Limitations}

The questionnaires were administered to groups of participants with different levels of motivation to respond in classrooms during school hours. Thus, the context in which the data we collected could cause reluctance in some adolescents and 
not all individuals approached a task with equal responsibility. We tried to prevent these risks by selecting a reasonable length for the questionnaire, "acceptable language", motivational elements, etc. The Czech version of the Teacher Support Scale unfortunately did not show the same or similar psychometric parameters as the original scale. For this reason, we had to continue working on the analyses only with an overall score that limited the possibility of deeper analysis. An adjustment to the Czech version of this tool is therefore worth considering, especially in the formulation of items, as well as an attempt to confirm the factor analysis again, for example, with another sample of respondents.

In our research, teacher support has been examined as a general "feeling" related to all teachers in school, so we cannot assess the individual teacher characteristics in relation to perceived support. We also did not analyze teacher support considering individual schools as the units of analysis. It is clear, however, that such a question could be a challenge for future analyses.

\section{Acknowledgements}

This study is an outcome of the research project "Career Adaptability of Vocational Upper-Secondary School Graduates During the School-to-Work Transition" (GA18-07537S) funded by the Czech Science Foundation.

\section{References}

Allee-Smith, P. J., Im, M. H., Hughes, J. N., \& Clemens, N. H. (2018). Mentor Support Provisions Scale: Measure dimensionality, measurement invariance, and associations with adolescent school functioning. Journal of School Psychology, 67, 69-87. https://doi.org/10.1016/j.jsp.2017.09.006

Brewster, A. B., \& Bowen, G. L. (2004). Teacher support and the school engagement of Latino middle and high school students at risk of school failure. Child and Adolescent Social Work Journal, 21(1), 47-67. https://doi.org/10.1023/B:CASW.0000012348.83939.6b

Bronfenbrenner, U. (1979). The Ecology of Human Development. London: Harvard University Press.

Caena, F. (2011). Literature review: Teachers' core competences: requirements and development. Data from: European Commission. Accessed January 19, 2019. https://ec.europa.eu/dgs/education.../teacher-competences_en.pdf

Caleon, I. S., Wui, G. L., Chiam, C. L., King, R. B., Tan, J. P., \& Tan, C. S. (2017). Personal strengths and perceived teacher support as predictors of Singapore students' academic risk status. Educational Psychology, 37(8), 983-1000. https://doi.org/10.1080/01443410.2016.1259460

Cooper, K. S. (2014). Eliciting engagement in the high school classroom: A mixed methods evaluation of teaching practices. American Educational Research Journal, 51(2), 363-402. https://doi.org/10.3102/0002831213507973

Cox, A., \& Williams, L. (2008). The role of perceived teacher support, motivational climate, and psychological need satisfaction in students' physical education motivation. Journal of Sport and Exercise Psychology, 30(2), 222-239. https://doi.org/10.1123/jsep.30.2.222

Czech Statistical Office. (2019). Population and Housing Census. Retrieved from https://www.czso.cz/ $\mathrm{csu} / \mathrm{czso} /$ population-and-housing-census

Deci, E. L., \& Ryan, R. M. (2000). The "what" and "why" of goal pursuits: Human needs and the self-determination of behavior. Psychological Inquiry, 11(4), 227-268. https://doi.org/10.1207/S15327965PLI1104_01

Dietrich, J., Dicke, A. L., Kracke, B., \& Noack, P. (2015). Teacher support and its influence on students' intrinsic value and effort: Dimensional comparison effects across subjects. Learning and Instruction, 39, 45-54. https://doi.org/10.1016/j.learninstruc.2015.05.007 
Di Fabio, A., \& Kenny, M. E. (2015). The contributions of emotional intelligence and social support for adaptive career progress among Italian youth. Journal of Career Development, 42(1), 48-59. https://doi.org/10.1177/0894845314533420

Faitar, G. M., \& Faitar, S. L. (2013). Teachers' influence on students's science career choices. American International Journal of Social Science, 2(5), 10-16.

Farmer, H. (1985). Model of career and achievement motivation for women and men. Journal of Counseling Psychology, 32(3), 363-390. https://doi.org/10.1037/0012-1649.14.3.268

Filak, V. F., \& Sheldon, K. M. (2008). Teacher support, student motivation, student need satisfaction, and college teacher course evaluations: Testing a sequential path model. Educational Psychology, 28(6), 711-724. https://doi.org/10.1080/01443410802337794

Guess, P. E., \& McCane-Bowling, S. J. (2016). Teacher support and life satisfaction: An investigation with urban, middle school students. Education and Urban Society, 48(1), 30-47. https://doi.org/10.1177/0013124513514604

Harter, S. (1985). Manual for the social support scale for children. Denver: University of Denver.

Hlad'o, P., \& Ježek, S. (2018). Measurement of career-specific parental behaviors perceived by Czech adolescents. Studia Paedagogica, 24(2), 101-135. https://doi.org/10.5817/SP2018-2-7

Hlad’o, P., Kvasková, L., Ježek, S., Hirshi, A., \& Macek, P. (2019). Career adaptability and social support of vocational students leaving upper secondary school. Journal of Career Assessment. https://doi.org/10.1177/1069072719884299

Hlad’o, P., Lazarová, B., \& Hloušková, L. (2019). Career adaptability of vocational education and training graduates in the period of prospective school-to-work transition. Studia paedagogica, 24(2), 59-83. https://doi.org/10.5817/SP2019-2-3

Johnson, D. W., \& Johnson, D. W. (1983). Social interdependence and perceived academic and personal support in the classroom. Journal of Social Psychology, 120(1), 77-82. https://doi.org/10.1080/00224545.1983.9712012

Kaur, P. (2012). Career maturity among adolescents in relation to their school climate. International Journal of Research in Education Methodology, 1(1), 10-13. https://doi.org/10.24297/ijrem.v1i1.4140

Kenny, M. E., \& Bledsoe, M. (2005). Contributions of the relational context to career adaptability among urban adolescents. Journal of Vocational Behavior 66(2), 257-272. https://doi.org/10.1016/j.jvb.2004.10.002

Klem, S. M., \& Connell, J. P. (2004). Relationships matter: Linking teacher support to student engagement and achievement. Journal of School Health, 74(7), 262-273. https://doi.org/10.1111/j.1746-1561.2004.tb08283.x

Lapan, R. T., Tucker, B., Se-Kang, B. K., \& Kosiulek, J. F. (2003). Preparing rural adolescents for post-high school transitions. Journal of Counseling and Development, 81(3), 329-342. https://doi.org/10.1002/j.1556-6678.2003.tb00260.x

Malecki, C. K., \& Demaray, M. K. (2002). Measuring perceived social support: Development of the Child and Adolescent Social Support Scale (CASSS). Psychology in the Schools, 39(1), 1-18. https://doi.org/10.1002/pits.10004

Malecki, C. K., \& Demaray, M. K. (2003). What type of support do they need? Investigating student adjustment as related to emotional, informational, appraisal, and instrumental support. School Psychology Quarterly, 18(3), 231-252. http://dx.doi.org/10.1521/scpq.18.3.231.22576

Mantzicopoulos, P. Z., \& Neuharth-Pritchett, S. (2003). Development and validation of a measure to assess Head Start children's appraisals of teacher support. Journal of School Psychology, 41(6), 431-451. https://doi.org/10.1016/j.jsp.2003.08.002

McNeely, C., \& Falci, C. (2004). School connectedness and the transition into and out of health- risk behavior among adolescents: A comparison of social belonging and teacher support. Journal of School Health, 74(7), 284-292. https://doi.org/10.1111/j.1746-1561.2004.tb08285.x

Metheny, J., McWhirter, E. H., \& O’Neil, E. (2008). Measuring perceived teacher support and its influence on adolescent career development. Journal of Career Assessment, 16(2), 218-237. https://doi.org/10.1177/1069072707313198

MEYS. (2018). Statistická ročenka školství - výkonové ukazatele [Statistical yearbook of education, the Ministry of Education, Youth and Sports]. Accessed January 20, 2018. http://toiler.uiv.cz/rocenka/rocenka.asp 
Mitchell, S. N., \& DellaMattera. J. N. (2010). Teacher support and student's self-efficacy beliefs. Journal of Contemporary Issues in Education, 5(2), 24-35. https://doi.org/10.20355/C5X30Q

Moos, R. H., \& Trickett. E. J. (1974). Classroom environment scale manual. Palo Alto, California: Consulting Psychologists Press. https://doi.org/10.1037/t06449-000

Perry, J. C., Liu, X., \& Pabian. Y. (2010). School engagement as a mediator of academic performance among urban youth: The role of career preparation, parental career support, and teacher support. The Counseling Psychologist 38(2), 269-295. https://doi.org/ 10.1177/0011000009349272

Research Assessment Package for Schools (RAPS) (1998). Institute for Research and Reform in Education. Rochester: University of Rochester. Accessed January 19, 2019. https://morandissertation.files.wordpress.com/2013/01/raps_manual_entire_19981.pdf

Reddy, R., Rhodes, J. E., \& Mulhall, P. (2003). The influence of teacher support on student adjustment in the middle school years: A latent growth curve study. Development and Psychopathology, 15(1), 119-138. https://doi.org/10.1017.S0954579403000075

Rogers, C. R. (1958). The characteristics of a helping relationship. The Personnel and Guidance Journal 37(1), 6-16. https://doi.org/10.1002/j.2164-4918.1958.tb01147.x

Rosseel, Y. (2012). lavaan: An R package for structural equation modeling. Journal of Statistical Software, 48(2), 1-36. https://doi.org/10.18637/jss.v048.i02

Ruzek, E. A., Hafen, C. A., Allen, J. P., Gregory, A., Mikami, A. Y., \& Pianta. R. C. (2016). How teacher emotional support motivates students: The mediating roles of perceived peer relatedness, autonomy support, and competence. Learning and Instruction 42, 95-103. https://doi.org/10.1016/j.learninstruc.2016.01.004

Ryan, A. M., \& Patrick, H. (2001). The classroom social environment and changes in adolescents' motivation and engagement during middle school. American Educational Research Journal, 38(2), 437-460. https://doi.org/10.3102/00028312038002437

Sakiz, G., Pape, S. J., \& Hoy, A.W. (2012). Does perceived teacher affective support matter for middle school students in mathematics classrooms? Journal of School Psychology, 50(2), 235-255. https://doi.org/10.1016/j.jsp.2011.10.005

Sarason, I. G., Levine, H. M., Basham, R., \& Sarason, B. (1983). Assessing social support: The social support questionnaire. Journal of Personality and Social Psychology, 44(1), 127-139. http://dx.doi.org/10.1037/0022-3514.44.1.127

Savickas, M. L. (2005). The theory and practice of career construction. In D. Brown \& R. W. Lent (Eds.), Career development and counseling: Putting theory and research to work (pp. 42-70). Hoboken: Wiley.

Savickas, M. L., \& Porfeli, E. J. (2012). Career Adapt-Abilities Scale: Construction, reliability, and measurement equivalence across 13 countries. Journal of Vocational Behavior, 80(3), 661-673. https://doi.org/10.1016/j.jvb.2012.01.011

Schiersmann, Ch., Ertelt, B.-J., Katsarov, J., Mulvey, R., Hazel, R., \& Weber, P. (2016). European competence standards for the academic training of career practitioners. Opladen, Berlin, and Toronto: Barbara Budrich Publishers. https://doi.org/10.2307/j.ctvd7w8vf

Suldo, S. M., Friedrich, A. A., White, T., Farmer, J., Minch, D., \& Michalowski, J. (2009). Teacher support and adolescents' subjective well-being: A mixed-methods investigation. School Psychology Review, 38(1), 67-85.

Tardy, C. H. (1985). Social support measurement. American Journal of Community Psychology, 13(2), 187-202. https://doi.org/10.1007/BF00905728

Torsheim, T., Wold, B., \& Samdal, O. (2000). The Teacher and Classmate Support scale. Factor structure, test-retest reliability and validity in samples of 13- and 15-year-old adolescents. School Psychology International, 21(2), 195-212. https://doi.org/10.1177/0143034300212006

Tsen, V., \& Seidman, E. (2007). A systems framework for understanding social settings. American Journal of Community Psychology, 39(3-4), 217-228. https:// doi: 10.1007/s10464-007-9101-8

Wang, M. T., \& Eccles, J. S. (2013). School context, achievement motivation, and academic engagement: A longitudinal study of school engagement using a multidimensional perspective. Learning and Instruction 28, 12-23. https://doi.org/10.1016/j.learninstruc.2013.04.002 
Weinstein, R. S., Marshall, H. H., Sharp, L., \& Botkin, M. (1987). Pygmalion and the student: Age and classroom differences in children's awareness of teacher expectations. Child Development, 58(4), 1079-1093. http://dx.doi.org/10.2307/1130548

Williams, G. C., \& Deci, E. L. (1996). Internalization of biopsychosocial values by medical students: A test of self-determination theory. Journal of Personality and Social Psychology, 70(4), 767-779. http://dx.doi.org/10.1037/0022-3514.70.4.767

Wold, B., Aarø, L. E., \& Smith, C. (1994). Health Behaviour in School Age Children. A WHO crossnational survey. Research protocol for the 1993-1994 study. Bergen: University of Bergen, Research Center for Health Promotion.

Zhang, J., Yuen, M., \& Chen, G. (2018). Teacher support for career development: An integrative review and research agenda. Career Development International 23(2), 122-144. https://doi.org/10.1108/CDI-09-2016-0155

Original manuscript received August 31, 2019 Revised manuscript accepted October 20, 2019

First published online November 15, 2019

To cite this article: Lazarová, B., Hlad’o, P., Hloušková, L. (2019). Perception of Teacher Support by Students in Vocational Education and Its Associations with Career Adaptability and Other Variables. Psychology in Russia: State of the Art, 12(4), 47-64. DOI: 10.11621/ pir.2019.0403 